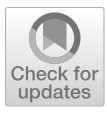

Cite as

Nano-Micro Lett.

(2020) $12: 87$

Received: 15 January 2020

Accepted: 28 February 2020

Published online: 6 April 2020

(C) The Author(s) 2020

\section{Interfacial Voids Trigger Carbon-Based, All-Inorganic CsPbIBr 2 Perovskite Solar Cells with Photovoltage Exceeding 1.33 V}

\author{
Weidong Zhu ${ }^{1}{ }^{凶}$, Zeyang Zhang ${ }^{1}$, Dandan Chen ${ }^{2}$, Wenming Chai ${ }^{1}$, Dazheng Chen ${ }^{1}$, \\ Jincheng Zhang ${ }^{1}$, Chunfu Zhang ${ }^{1}{ }^{凶}$, Yue Hao ${ }^{1}$ \\ Weidong Zhu and Zeyang Zhang have contributed equally to this work. \\ $\triangle$ Weidong Zhu,wdzhu@xidian.edu.cn; Chunfu Zhang, cfzhang@xidian.edu.cn \\ 1 State Key Discipline Laboratory of Wide Band Gap Semiconductor Technology and Shaanxi \\ Joint Key Laboratory of Graphene, School of Microelectronics, Xidian University, Xi' an 710071, \\ People's Republic of China \\ 2 College of Science, Xi' an Shiyou University, Xi'an 710065, Shaanxi, People's Republic of China
}

\title{
HIGHLIGHTS
}

- A novel interface design of producing interfacial voids is proposed for $\mathrm{CsPbIBr}_{2}$ perovskite solar cells (PSCs), which is free of any extra modification layer.

- Interfacial voids improve absorption of $\mathrm{CsPbIBr}_{2}$ film, reduce saturation current density, and enlarge built-in potential of the PSCs.

- The PSC yields a superior efficiency of $10.20 \%$ with a record-high photovoltage of $1.338 \mathrm{~V}$.

\begin{abstract}
A novel interface design is proposed for carbon-based, all-inorganic $\mathrm{CsPbIr}_{2}$ perovskite solar cells (PSCs) by introducing interfacial voids between $\mathrm{TiO}_{2}$ electron transport layer and $\mathrm{CsPbIBr}_{2}$ absorber. Compared with the general interfacial engineering strategies, this design exempts any extra modification layer in final PSC. More importantly, the interfacial voids produced by thermal decomposition of 2-phenylethylammonium iodide trigger three beneficial effects. First, they promote the light scattering in $\mathrm{CsPbIB}_{2}$ film and thereby boost absorption ability of the resulting $\mathrm{CsPbIBr}_{2}$ PSCs. Second, they suppress recombination of charge carriers and thus reduce dark saturation current density $\left(J_{0}\right)$ of the PSCs. Third, interfacial voids enlarge built-in potential $\left(V_{\mathrm{bi}}\right)$ of the PSCs, awarding increased driving force for dissociating photo-generated charge carriers. Consequently, the PSC yields the optimized efficiency of $10.20 \%$ coupled with an open-circuit voltage $\left(V_{\text {oc }}\right)$ of $1.338 \mathrm{~V}$. The $V_{\text {oc }}$ achieved herein
\end{abstract}

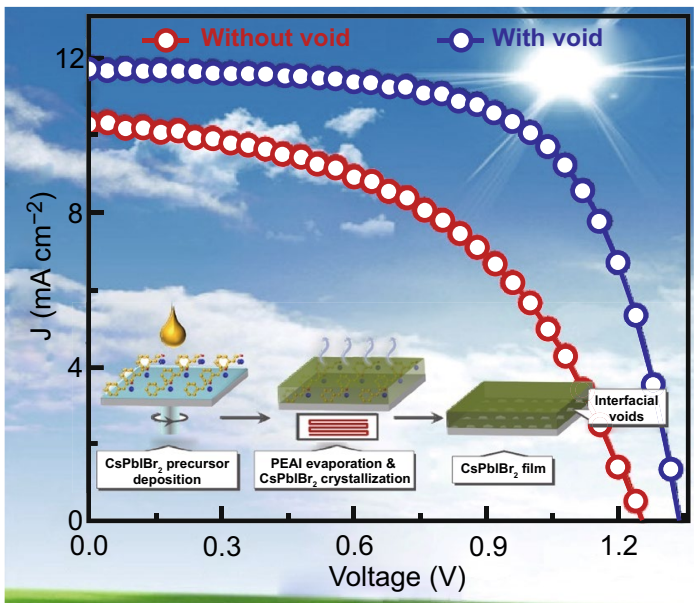
represents the best value among $\mathrm{CsPbIBr}_{2}$ PSCs reported earlier. Meanwhile, the non-encapsulated PSCs exhibit an excellent stability against light, thermal, and humidity stresses, since it remains $\sim 97 \%$ or $\sim 94 \%$ of its initial efficiency after being heated at $85{ }^{\circ} \mathrm{C}$ for $12 \mathrm{~h}$ or stored in ambient atmosphere with relative humidity of $30-40 \%$ for 60 days, respectively.

KEYWORDS All-inorganic perovskite solar cells; $\mathrm{CsPbIBr}_{2}$; Photovoltage; Interfacial engineering; Stability 


\section{Introduction}

Organic-inorganic hybrid perovskite semiconductors have emerged as promising absorber materials for solar cells that are known as perovskite solar cells (PSCs), owing to their excellent optoelectronic properties, low cost, and versatile low-temperature processability of thin films [1-4]. Furthermore, the certified power conversion efficiency (PCE) of PSCs has reached up to $25.2 \%$ [5], approaching that of commercial crystalline silicon solar cells. However, the poor stability of organic-inorganic hybrid perovskite films under thermal, humidity, and light stresses brings a severe reliability issue to PSCs $[3,4,6]$. In addition, most of highefficiency PSCs generally contain expensive and unstable organic hole transport layers (HTLs) coupled with noble metal electrodes. These functional films not only aggravate the instability problem but also burden the production cost of corresponding PSCs $[3,6,7]$. Hence, there is a growing attention to carbon-based, all-inorganic PSCs that avoid use of any HTLs and noble metal electrodes, in view of their multiply superiorities including upgraded stability, costeffectiveness, and facile fabrication [7-11].

Currently, the absorber materials explored for carbonbased, all-inorganic PSCs largely include $\mathrm{CsPbI}_{3}[12,13]$, $\mathrm{CsPbI}_{2} \mathrm{Br}$ [14-16], $\mathrm{CsPbIBr}_{2}$ [8, 17-20], and $\mathrm{CsPbBr}_{3}$ [7, 9, 21-23]. Among them, $\mathrm{CsPbIBr}_{2}$ holds the relatively well-balanced characters of bandgap and phase stability [8, 17-19, 24, 25]. Meanwhile, $\mathrm{CsPbIBr}_{2}$ is also applicable to build photovoltaic windows [26], semitransparent solar cells [27], water splitting systems [28], and tandem solar cells in conjunction with the state-of-the-art photovoltaic technologies [11]. Nevertheless, the PCEs of carbon-based, all-inorganic $\mathrm{CsPbIBr}_{2}$ PSCs are still far from their theoretical level [29, 30], and even lag behind that of the ones based on other analogs $[13,15,23]$. This dilemma can be largely attributed to their inferior open-circuit voltage $\left(V_{\mathrm{oc}}\right)$ and fill factor $(\mathrm{FF})$ values, which are eventually caused by the serious non-radiative recombination within $\mathrm{CsPbIBr}_{2}$ films and interfacial recombination in the PSCs.

To solve the above obstacles, great efforts have been dedicated in improving the quality of $\mathrm{CsPbIBr}_{2}$ films, targeting to suppress non-radiative recombination of charge carriers, by crystallization engineering or heteroatom replacement on $\mathrm{Cs}$ site or $\mathrm{Pb}$ site $[19,20,25,31]$. For example, our previous work [19] demonstrated that modification of general one-step method with an intermolecular exchange reaction could produce a pinhole-free $\mathrm{CsPbIBr}_{2}$ film composed of micro-sized, [100] preferential grains, which finally enabled an optimized PCE of $9.16 \%$. More recently, it was reported that $\mathrm{Ba}(\mathrm{II})$ doping could boost the grain sizes and crystallinity of $\mathrm{CsPbIBr}_{2}$ film, bringing out reduced trap states and suppressed non-radiative recombination. As a result, the PCE of corresponding PSC was boosted from 8.40 to $10.51 \%$ [31].

Interfacial modification with extra functional materials has been attempted to weaken interfacial recombination of charge carriers and therefore improve the PCEs of $\mathrm{CsPbIBr}_{2}$ PSCs [17, 18, 30, 32]. For example, the innovative modification of $\mathrm{TiO}_{2}$ electron transport layer (ETL) with $\mathrm{CsBr}$ or $\mathrm{SmBr}_{3}$ could strikingly improve the PSC's PCE to over $10 \%$ coupled with desirable FF of $\sim 0.70$, which represents the highest PCE among $\mathrm{CsPbIBr}_{2}$ PSCs reported to date [18, 30]. Guo et al. [17] reported that surficial passivation of $\mathrm{SnO}_{2}$ ETL could enable the $\mathrm{CsPbIBr}{ }_{2}$ PSCs with a recordhigh $V_{\text {oc }}$ of $1.31 \mathrm{~V}$ in spite of its low PCE of $2.06 \%$. Clearly, these progresses verify the considerable feasibility of interfacial modification strategy in overcoming the obstacle faced by carbon-based, all-inorganic $\mathrm{CsPbIBr}_{2}$ PSCs. However, the extra interfacial modifiers inevitably complex the configuration of $\mathrm{CsPbIBr}{ }_{2}$ PSCs and thus bring some new parasitic issues. For example, the modifiers multiply the interfaces of $\mathrm{CsPbIBr}{ }_{2}$ PSCs, leading to an increased degradation risk [3, 33, 34]. Meanwhile, they will also alter the crystallization dynamics of atop $\mathrm{CsPbIBr}_{2}$ films [35, 36], which brings a new challenge to prepare high-quality $\mathrm{CsPbIBr}$ film. Thus, it is highly desired to develop more feasible interfacial engineering strategy to boost interfacial kinetics of charge carriers in carbon-based, all-inorganic $\mathrm{CsPbIBr}_{2} \mathrm{PSCs}$, thereby boosting its $V_{\mathrm{oc}}$ and FF as well as PCE.

In this study, we propose an interfacial engineering strategy for carbon-based, all-inorganic $\mathrm{CsPbIBr}_{2}$ PSCs by making interfacial voids between $\mathrm{TiO}_{2} \mathrm{ETL}$ and $\mathrm{CsPbIBr}_{2}$ film. This strategy avoids introducing any extra modification layer in ultimate PSCs compared with the conventional ones. Further, we reveal that the interfacial voids can stimulate enhanced absorption, decreased interfacial recombination of charge carriers, as well as enlarged built-in potential $\left(V_{\mathrm{bi}}\right)$ in resulting $\mathrm{CsPbIBr}_{2}$ PSCs. Hence, the optimized one yields the outstanding PCE of $10.20 \%$ coupled with a high $V_{\text {oc }}$ of $1.338 \mathrm{~V}$, a FF of 0.65 , and a short-circuit current density $\left(J_{\mathrm{sc}}\right)$ of $11.73 \mathrm{~mA} \mathrm{~cm}^{-2}$. The PCE is beyond nearly most of 
$\mathrm{CsPbIBr}_{2}$-based cells reported earlier, and particularly the $V_{\text {oc }}$ represents the highest level among them. Moreover, the PSC exhibits excellent photo-stability as well as long-term stability against thermal and humidity stresses.

\section{Experimental Section}

\subsection{Materials and Reagents}

Patterned FTO glass substrates (Pilkington, TEC-8, $8 \Omega \mathrm{sq}^{-1}$ ) were supplied by Yingkou OPV Tech New Energy Co., Ltd., China. Conductive carbon paste was bought from Shanghai MaterWin New Materials Co., Ltd., China. Lead bromide $\left(\mathrm{PbBr}_{2}\right.$, ultra-dry, 99.999\%), cesium iodide (CsI, ultra-dry, 99.998\%), and dimethyl sulfoxide (DMSO, anhydrous, $99.8+\%$ ), isopropanol (anhydrous, $99.5+\%$ ) are received from Alfa-Assar. 2-phenylethylammonium iodide (PEAI, 99.99\%) was purchased from Xi'an Polymer Light Technology Co., Ltd., China. All of them are used without further treatment or purification.

\subsection{Preparation of PEAI-Loaded $\mathrm{FTO} / \mathrm{TiO}_{2}$ Substrate}

Firstly, patterned FTO glass with size $2 \times 2.5 \mathrm{~cm}^{2}$ was washed with detergent, ultrapure water, acetone, and ethanol in an ultrasonic cleaner successively. $\mathrm{Next}, \mathrm{TiO}_{2}$ sol was spin coated onto the FTO glass at $3500 \mathrm{rpm}$ for $30 \mathrm{~s}$. After being annealed at $500{ }^{\circ} \mathrm{C}$ for $60 \mathrm{~min}$ in ambient air, the $\mathrm{FTO} / \mathrm{TiO}_{2}$ substrate was achieved. Finally, $100 \mu \mathrm{L} 3 \mathrm{mg} \mathrm{mL}^{-1} \mathrm{PEAI}$ in isometric deionized water and isopropanol was spin-coated on the substrate at $3500 \mathrm{rpm}$ for $60 \mathrm{~s}$ and baked at $80{ }^{\circ} \mathrm{C}$ for 5 min in ambient air in order to load PEAI species onto $\mathrm{FTO} / \mathrm{TiO}_{2}$ substrate.

\subsection{Deposition of $\mathrm{CsPbIBr}_{2}$ Film}

CsPbIBr 2 precursor $(1.0 \mathrm{M})$ was firstly prepared by dissolving $370.0 \mathrm{mg} \mathrm{PbBr}_{2}$ and $260.0 \mathrm{mg} \mathrm{CsI}$ in $1 \mathrm{~mL}$ DMSO at room temperature with vigorously stirring. Then, the PEAIloaded $\mathrm{FTO} / \mathrm{TiO}_{2}$ substrate was transferred into a $\mathrm{N}_{2}$-filled glovebox. And, $70 \mu \mathrm{L} \mathrm{CsPbIBr}$ precursor was spin-coated the substrate at $1500 \mathrm{rpm}$ for $20 \mathrm{~s}$ and $5000 \mathrm{rpm}$ for $60 \mathrm{~s}$. After the spin-coating process, the sample was annealed at $280{ }^{\circ} \mathrm{C}$ for $15 \mathrm{~min}$ to form the crystallized $\mathrm{CsPbIBr}_{2}$ film. For comparison, a $\mathrm{CsPbIBr}{ }_{2}$ film on $\mathrm{FTO} / \mathrm{TiO}_{2}$ substrate without loading of PEAI species was also prepared according to the same procedures above.

\subsection{Fabrication of Carbon-Based, All-Inorganic PSC}

Carbon paste with the area of $0.10 \mathrm{~cm}^{2}$ was firstly coated on $\mathrm{CsPbIBr}_{2}$ film by screen-printing method. Then, the sample was heated at $120{ }^{\circ} \mathrm{C}$ for $15 \mathrm{~min}$ to promote evaporation of solvent of carbon paste. After cooling down naturally to room temperature, the carbon-based, all-inorganic PSC was achieved for further characterizations.

\section{Results and Discussion}

\subsection{Formation Mechanism of $\mathrm{CsPbIBr}_{2}$ Films with Interfacial Voids}

The main preparation procedures of $\mathrm{CsPbIBr}_{2}$ film with interfacial voids are shown in Scheme 1. To be brief, FTO/ $\mathrm{TiO}_{2}$ substrate was firstly prepared according to the recipe described in our previous work [18, 19]. Then, 2-phenylethylammonium iodide (PEAI, $\mathrm{C}_{6} \mathrm{H}_{5} \mathrm{CH}_{2} \mathrm{CH}_{2} \mathrm{NH}_{3} \mathrm{I}$ ) in isometric deionized water and isopropanol was deposited on

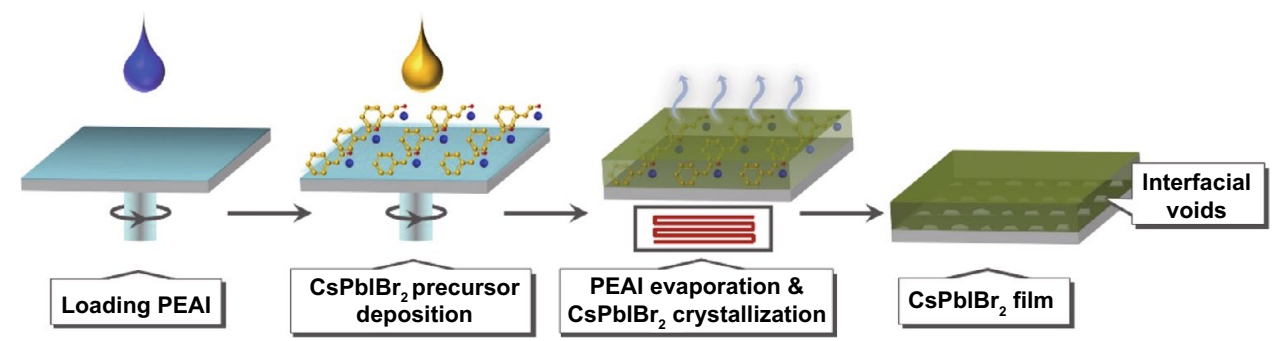

Scheme 1 Schematic procedures for preparation of $\mathrm{CsPbIBr}_{2}$ film with interfacial voids 
FTO/TiO ${ }_{2}$ substrate by spin-coating method, with the aim of loading PEAI species on $\mathrm{TiO}_{2}$ surface. The successful loading of PEAI can be verified by the scanning electron microscope (SEM) results in Fig. S1. Next, $\mathrm{CsPbIBr}_{2}$ precursor was spin-coated onto the substrate by one-step spincoating method. Finally, the sample was annealed at $280{ }^{\circ} \mathrm{C}$ for $15 \mathrm{~min}$ to promote the crystallization of $\mathrm{CsPbIBr}_{2}$ grains. It is noted that the release of PEAI species happened simultaneously during this high-temperature annealing stage, as discussed below.

We conducted X-ray photoelectron spectroscopy (XPS) measurement to examine the constituents of obtained $\mathrm{CsPbIBr}_{2}$ film. For comparison, a same $\mathrm{CsPbIBr}_{2}$ film that was prepared at a low annealing temperature of $100{ }^{\circ} \mathrm{C}$ was also investigated. The reason for adopting this low annealing temperature to prepare the control sample is that it cannot cause the sublimation or decomposition of PEAI molecules, as demonstrated previously [37, 38]. Figure 1a manifests that clear XPS peaks corresponding to $\mathrm{Cs}, \mathrm{Pb}, \mathrm{I}$, and $\mathrm{Br}$ elements appear for the films annealed at either 280 or $100{ }^{\circ} \mathrm{C}$, indicating that they are composed of $\mathrm{CsPbIBr}_{2}$ materials. However, no any signal corresponding to PEAI species can be measured from them, even though the $\mathrm{FTO} / \mathrm{TiO}_{2}$ substrate contains PEAI species. The core-level N $1 s$ XPS spectra in Fig. $1 \mathrm{~b}$ further verify this fact, since the typical $\mathrm{N} 1 s$ peak of PEAI species is absent [38].

In general, XPS measurement can only reflect surficial composition information of samples. To insight bulk composition of the concerned $\mathrm{CsPbIBr}_{2}$ films, they were redissolved in situ by $N, N$-dimethylformamide (DMF) solvent and annealed again at $90{ }^{\circ} \mathrm{C}$ for $10 \mathrm{~min}$ to evaporate the solvent away. As shown in Fig. 1a, after such treatment the additional $\mathrm{Sn} 3 d$ peaks that originate from $\mathrm{FTO} / \mathrm{TiO}_{2}$ substrate can be detected from both films, indicating the full dissolution of $\mathrm{CsPbIBr}_{2}$ films by DMF solvent and therefore the possible non-uniform composition distribution in the films or their interfaces is eliminated. In this manner, XPS measurement can be used to study bulk composition of $\mathrm{CsPbIBr}_{2}$ films reasonably. Once again, as exhibited in Fig. 1b, the $\mathrm{N}$ $1 s$ peak located at $401.8 \mathrm{eV}$ can be detected from $\mathrm{CsPbIBr}_{2}$ film prepared at $100{ }^{\circ} \mathrm{C}$, manifesting the existence of PEAI species in it [37, 38]. By contrast, the peak is still missing in $\mathrm{CsPbIBr}_{2}$ film prepared at $280{ }^{\circ} \mathrm{C}$, indicating that there is no detectable PEAI species in it indeed. This can
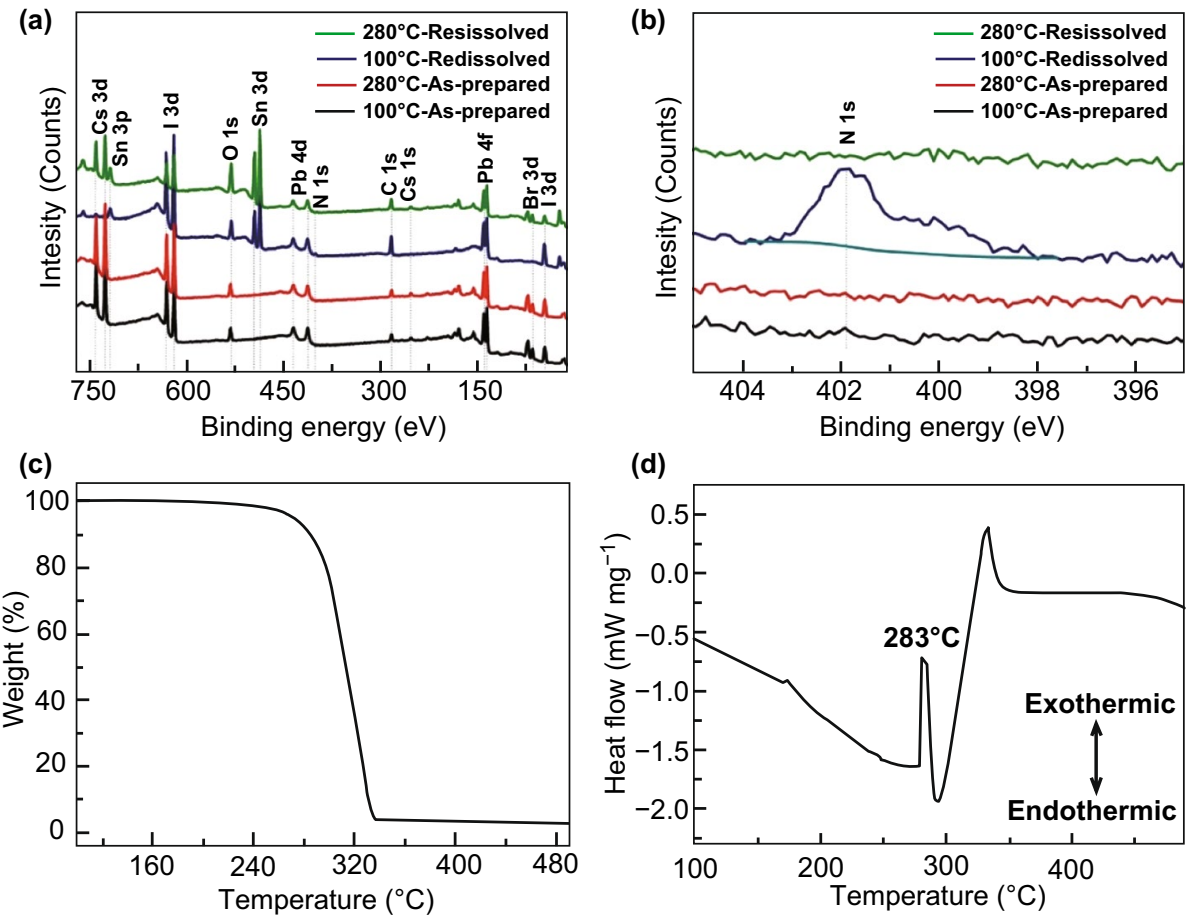

(d)

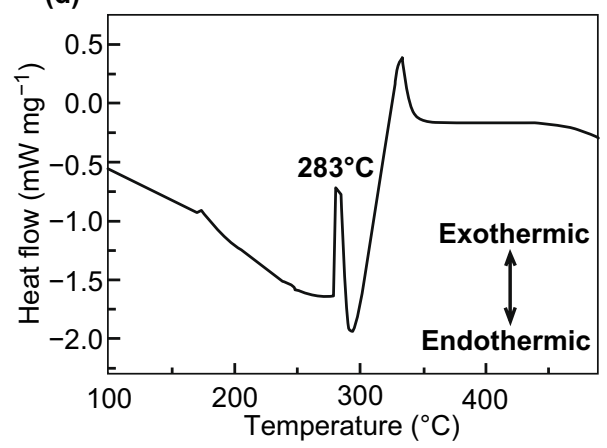

Fig. 1 a XPS survey spectra of as-prepared and in situ redissolved $\mathrm{CsPbIBr}_{2}$ films annealed at $100{ }^{\circ} \mathrm{C}$ and $280{ }^{\circ} \mathrm{C}$, b corresponding core-level $\mathrm{N}$ $1 s$ XPS spectra, $\mathbf{c}$ TGA heating curve of PEAI powder expressed as weight $\%$ as a function of applied temperature, $\mathbf{d}$ DSC curve of PEAI powder 
be also supported by the energy-dispersive spectrometer (EDS) result in Fig. S2. We attribute such phenomenon to the sublimation of PEAI species during the high-temperature annealing stage of $\mathrm{CsPbIBr}_{2}$ film.

To support our standpoint, thermal property of PEAI powder was investigated by thermogravimetric analysis (TGA) and differential scanning calorimetry (DSC) [39, 40]. The TGA curve in Fig. 1c indicates that PEAI powder undergoes $100 \%$ weight loss in one step with the onset temperature of $\sim 185{ }^{\circ} \mathrm{C}$, suggesting that it is sublimated without complex decomposition procedure. This can be supported by the sharp transition step in corresponding differential TGA curve in Fig. S3. Moreover, the endothermic peak at $\sim 283{ }^{\circ} \mathrm{C}$ in the DSC curve in Fig. $1 \mathrm{~d}$ also suggests that the release of PEAI is related to a sublimation process. Thus, the typical sublimation temperature of PEAI powder is estimated to be $\sim 283{ }^{\circ} \mathrm{C}$, which is nearly the same as the annealing temperature of $\mathrm{CsPbIBr}_{2}$ film adopted in this work. Additionally, it is noted that the DSC measurement was performed on PEAI powder. In the case of within $\mathrm{CsPbIBr}_{2}$ thin film, a much larger surface-to-volume ratio is provided; therefore, the sublimation temperature could be lowered considerably to below $\sim 283{ }^{\circ} \mathrm{C}$ for PEAI. Thus far, all the above observations provide conclusive evidences that in terms of $\mathrm{CsPbIBr}$ film prepared at $280{ }^{\circ} \mathrm{C}$ the original PEAI species on $\mathrm{FTO} / \mathrm{TiO}_{2}$ substrate do not reside in its bulk or at its interface, but are sublimated during the thermal annealing stage.

\subsection{Morphology Characterization}

With this fact in mind, we turned to study the microstructure of $\mathrm{CsPbIBr}{ }_{2}$ films deposited on $\mathrm{FTO} / \mathrm{TiO}_{2}$ substrates without and with loading of PEAI species. Their top-view SEM images are provided in Fig. 2a, b. Clearly, both films are composed of closely packed crystalline grains without any discernible pinholes. Their grains are featured by dominant triple-junctions grain boundaries with equal vertex angle of $120^{\circ}$, implying that they are in equilibrium state with low internal stress [41, 42]. By contrast, the $\mathrm{CsPbIBr}_{2}$ film deposited on $\mathrm{FTO} / \mathrm{TiO}_{2}$ substrate loaded with PEAI species exhibits larger grain sizes. The statistical results in Fig. S4 indicate its average grain size of $\sim 576 \mathrm{~nm}$, which is slightly larger than the one deposited on $\mathrm{FTO} / \mathrm{TiO}_{2}$ substrate without loading of PEAI species ( $475 \mathrm{~nm})$. It should be noted that the formation of coarsened grains is mainly attributed
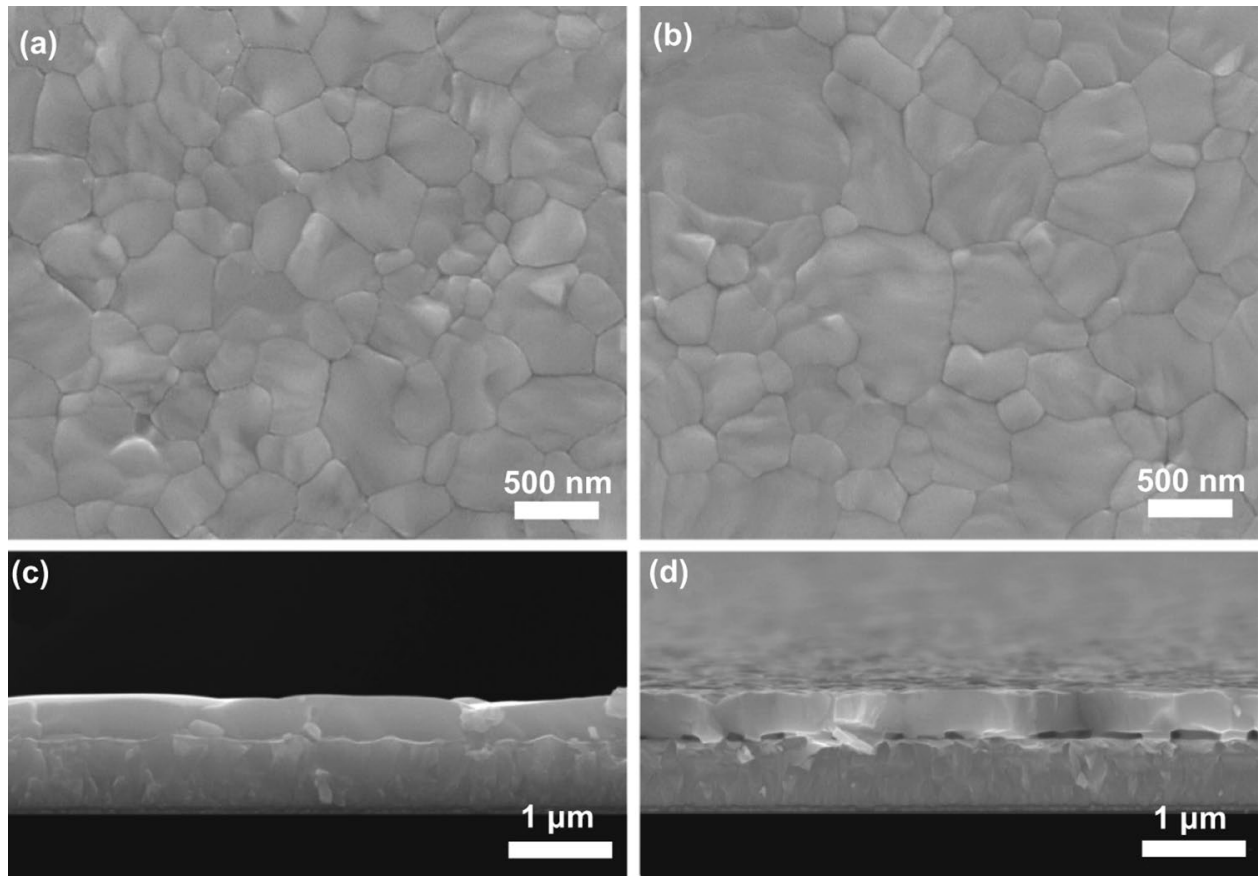

Fig. 2 Top-view and cross-sectional SEM images of $\mathrm{CsPbIBr}_{2}$ films deposited on $\mathrm{FTO} / \mathrm{TiO}_{2}$ substrates: a, $\mathbf{c}$ without and $\mathbf{b}$, $\mathbf{d}$ with loading of PEAI species 
to the decreased nucleation density of $\mathrm{CsPbIBr}_{2}$ grains, as a result of improved non-wetting of $\mathrm{CsPbIBr}_{2}$ precursor to FTO/TiO ${ }_{2}$ substrate induced by PEAI species (Fig. S5) [36, 43], along with the templating effect of PEAI species during the crystallization of $\mathrm{CsPbIBr}_{2}$ grains.

Figures 2c, d and S6 provide cross-sectional SEM images of the concerned $\mathrm{CsPbIBr}_{2}$ films. They reveal that the films have a similar thickness of $\sim 400 \mathrm{~nm}$. And, each of individual grains in the films is able to vertically penetrate entire film thickness. Such feature maybe endow excellent transport behavior of charge carriers along them, since the transport and transfer of charge carriers do so without traversing any grain boundaries in this case $[4,41]$. By comparison, interfacial microstructure of these two films differs obviously. For the $\mathrm{CsPbIBr}{ }_{2}$ film deposited on $\mathrm{FTO} / \mathrm{TiO}_{2}$ substrate without loading PEAI species, the interface between $\mathrm{CsPbIBr}_{2}$ film and $\mathrm{FTO} / \mathrm{TiO}_{2}$ substrate is contacted seamlessly. However, there are many voids that have the typical size of $\sim 100 \mathrm{~nm}$ in the same interface, in terms of $\mathrm{CsPbIr}_{2}$ film deposited on $\mathrm{FTO} / \mathrm{TiO}_{2}$ substrate loaded with PEAI species. These voids give rise to the rough contact interface between $\mathrm{CsPbIBr}_{2}$ film and $\mathrm{FTO} / \mathrm{TiO}_{2}$ substrate. It is also noted that because PEAI species are sublimated during the thermal annealing stage of $\mathrm{CsPbIBr}_{2}$ film, we conclude that the pre-deposited PEAI species likely act as pore-forming agent in the present case. The strategy of using pore-forming agent has been widely used to create pores in traditional ceramic materials $[44,45]$. Our viewpoint can be further supported by the cross section SEM image of the same $\mathrm{CsPbIr}_{2}$ film prepared with large concentration of PEAI solution $\left(10 \mathrm{mg} \mathrm{mL}^{-1}\right)$, as provided in Fig. S7. It is clear that the voids with much larger sizes are produced when the more PEAI species were predeposited. Overall, the PEAI species on $\mathrm{FTO} / \mathrm{TiO}_{2}$ substrate, serving as pore-forming agent, can promote the formation of large-sized grains in ultimate $\mathrm{CsPbIr}_{2}$ film as well as some voids at the interface between $\mathrm{CsPbIBr}_{2}$ film and FTO/ $\mathrm{TiO}_{2}$ substrate.

\subsection{Crystalline and Optical Property Analysis}

Next, the crystalline structure and optical properties of asprepared $\mathrm{CsPbIBr}_{2}$ films are investigated. For clarification, the $\mathrm{CsPbIBr}$ film as well the cell deposited on $\mathrm{FTO} / \mathrm{TiO}_{2}$ substrate without loading of PEAI species are labeled as "without void," and the ones on $\mathrm{FTO} / \mathrm{TiO}_{2}$ substrate with loading of PEAI species are named as "with voids" hereinafter. Figure 3a presents X-ray diffraction (XRD) patterns of $\mathrm{CsPbIBr}_{2}$ films without and with interfacial voids. Both samples exhibit the pure cubic perovskite phase, since the diffraction peaks at $15.1^{\circ}, 21.4^{\circ}, 26.6^{\circ}, 30.4^{\circ} 33.8^{\circ}$, and $37.8^{\circ}$ are well consistent with those of (100), (110), (111), (200), (210), and (211) planes of $\mathrm{CsPbIBr}_{2}$ crystals reported previously [10, 26]. Meanwhile, the XRD peaks of (100) and (200) planes are dominantly intense for both samples, indicating that the grains in them have (100)-preferential orientation. For cubic perovskite polycrystalline films, $\{100\}$ grains facets are generally along the direction perpendicular to $\mathrm{FTO} / \mathrm{TiO}_{2}$ substrate, which well coincides the vertically penetrated grains morphology observed in the cros section SEM images in Figs. 2c, d and S6 for the concerned $\mathrm{CsPbIBr}$ films. In addition, the dominant diffraction peaks of $\mathrm{CsPbIBr}_{2}$ film with interfacial voids are more intense than the one without voids, and the full-width-at-half-maximum (FWHM) values of its (100) and (200) XRD peaks are smaller (Table S1). These results reveal the better crystallinity with fewer intragranular defects and less scattering of grain boundaries for the $\mathrm{CsPbIBr}$ film with interfacial voids, in consideration of the similar thickness of the two films [22, 41, 43]. Such features are in accordance with the larger grains of $\mathrm{CsPbIr}_{2}$ film with interfacial voids.

Figure $3 b$ presents the ultraviolet-visible (UV-vis) spectra of as-prepared $\mathrm{CsPbIBr}_{2}$ films. Both of them exhibit the typical absorption features of $\mathrm{CsPbIBr}{ }_{2}$ materials including the exciton absorption peak at $\sim 560 \mathrm{~nm}$ and absorption edge of $\sim 599 \mathrm{~nm}$ that is in accordance with the bandgap of $\mathrm{CsPbIBr}_{2}(2.07 \mathrm{eV})[20,25,27]$. In comparison, the $\mathrm{CsPbIBr}{ }_{2}$ film with interfacial voids shows higher absorption intensities in the whole absorption ranges, revealing its better light absorption capacity. In principle, this desired feature mainly originates from either improved quality of $\mathrm{CsPbIBr}$ film or scattering effect of interfacial voids in it, in view of the similar thickness of the two films. To exclude the effect of the former, UV-vis characters of the concerned $\mathrm{CsPbIBr}_{2}$ films were collected from the side of FTO glass, wherein the detection beam streams from the top surface of $\mathrm{CsPbIBr}_{2}$ films. The results in Fig. S8 reveal that the differences of their absorption intensities decrease accordingly. That is to say, the better absorption ability of $\mathrm{CsPbIBr}_{2}$ film with interfacial voids observed in Fig. $3 b$ largely comes from the beneficial scattering effect of interfacial voids, which may make great contribution to $J_{\mathrm{sc}}$ of ultimate PSC. 

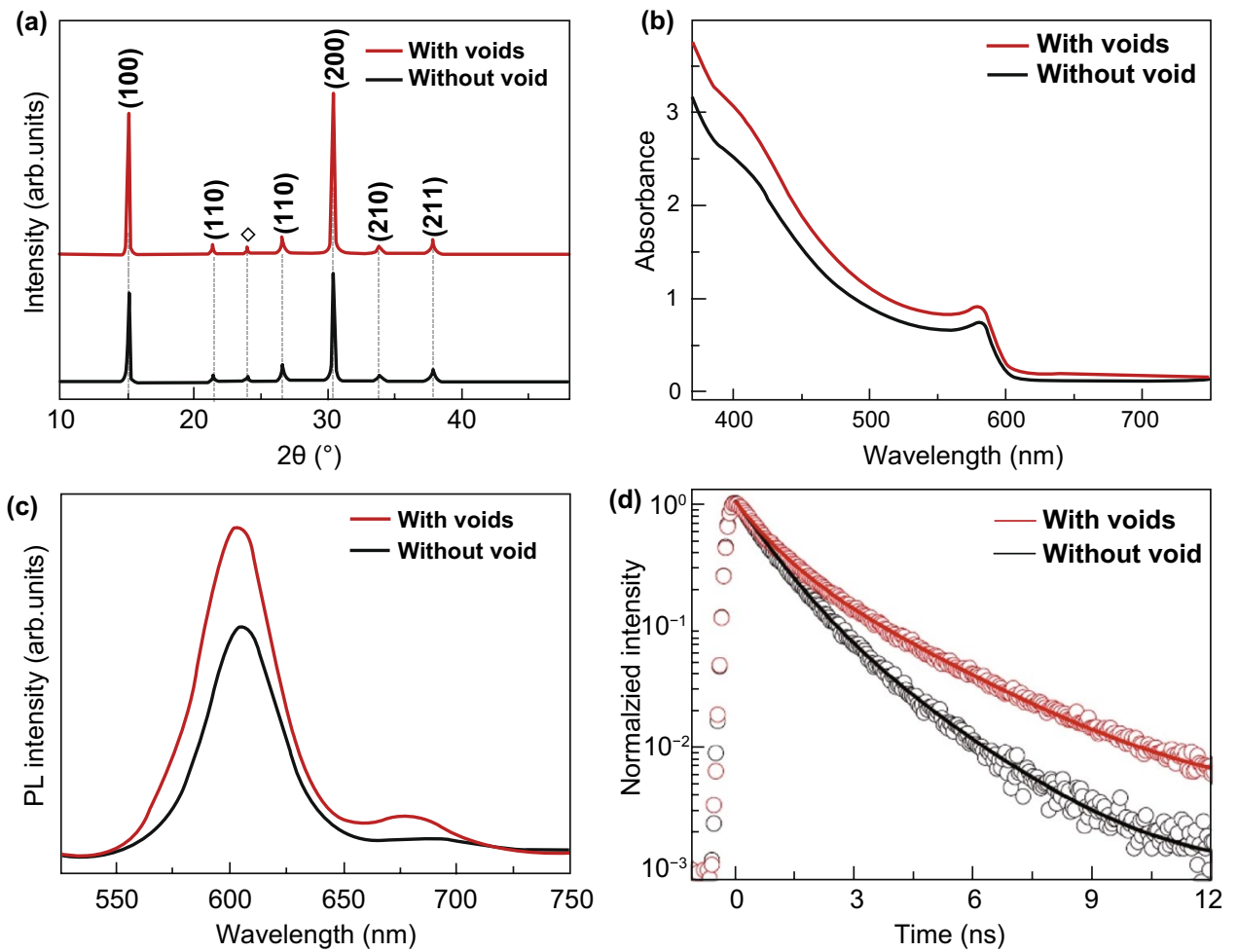

Fig. 3 a XRD patterns and b UV-vis absorption spectra of $\mathrm{CsPbIBr}_{2}$ films without and with interfacial voids, $\mathbf{c}$ steady-state PL spectra and $\mathbf{d}$ TRPL curves of $\mathrm{CsPbIBr}$ films without and with interfacial voids on insulating glass substrates instead of $\mathrm{FTO} / \mathrm{TiO}_{2}$ substrates

Figure 3c, d gives steady-state photoluminescence (PL) spectra and time-resolved PL (TRPL) curves of $\mathrm{CsPbIBr}_{2}$ films without and with interfacial voids grown on insulating glass substrates instead of $\mathrm{FTO} / \mathrm{TiO}_{2}$ substrates, respectively. As shown in Fig. 3c, $\mathrm{CsPbIBr}_{2}$ films exhibit the dominant PL peaks at $\sim 600 \mathrm{~nm}$, in well agreement with their bandgaps. The shoulder peaks can be also observed for both samples, as indicated by the logarithmic-scale PL plots in Fig. S9. This phenomenon is mainly caused by light-induced halide phase segregation in $\mathrm{CsPbIBr}_{2}$ films, wherein some I-rich domains with low bandgap and $\mathrm{Br}$-rich domains with wide bandgap are formed under illumination, as demonstrated in previous works [19, 46-48]. In addition, the $\mathrm{CsPbIBr}_{2}$ film with interfacial voids yields the stronger PL peak intensity, revealing the weaker non-radiative recombination of charge carriers in it. Figure 3d shows the corresponding TRPL results, which can provide semi-quantitative information about non-radiative recombination of charge carriers $[2,4,9$, 48]. The curves are fitted by a bi-exponential decay function of time ( $t)[2,4]: F(t)=\sum A_{i} e^{\tau / \tau^{i}} ; i=1,2$, in which $A_{\mathrm{i}}$ and $t_{\mathrm{i}}$ are weight factor and time constant, respectively. In this manner, the average carrier lifetime $\left(t_{\text {ave }}\right)$ can be estimated according to the equation of $\tau_{\text {ave }}=\sum A_{i} \tau_{i}^{2} / \sum A_{i} \tau_{i} ; i=1,2$. The $\mathrm{CsPbIBr}_{2}$ film with interfacial voids exhibits the $\tau_{\text {ave }}$ of $1.91 \mathrm{~ns}$, which is higher than the one without interfacial voids $(1.26 \mathrm{~ns})$. The longer $\tau_{\text {ave }}$ of the former indicates the fewer defects in it, which is originally attributed to the larger grains and better crystallinity of $\mathrm{CsPbIBr}{ }_{2}$ film with interfacial voids.

\subsection{Photovoltaic Performance}

Hitherto, we reveal that the $\mathrm{CsPbIBr}$ film with interfacial voids has slightly larger grains and higher crystallinity, which result in the weaker non-radiative recombination of charge carriers in it. Such feature is expected to improve the $V_{\text {oc }}$ and FF of ultimate PSC [18, 30, 32, 49]. Meanwhile, the interfacial voids trigger intense light scattering effect [50], which gives rise to the much higher absorption of the $\mathrm{CsPbIBr}_{2}$ film and hence maybe boost the $J_{\mathrm{sc}}$ of corresponding PSC. It is generally recognized that interfacial voids are harmful to the performance of planar PSC, since 
they inevitably reduce the contact area between absorber film and charge transporting layer, thus increasing the transporting resistance of charge carriers. Even so, in the present case, we speculate that such negative effect can be fully counteracted by the multiply beneficial contributions of the interfacial voids described above. To verify our inference, the $\mathrm{CsPbIB}_{2}$ films without and with interfacial voids are used to construct carbon-based, all-inorganic PSCs with the structure of $\mathrm{FTO} / \mathrm{TiO}_{2} / \mathrm{CsPbIBr}_{2} /$ Carbon as illustrated in Fig. 4a. Firstly, the PEAI solution concentration was optimized according to the performance of resulting PSCs. As shown in Fig. 4b, the PSC yields the optimized PCE when $3 \mathrm{mg} \mathrm{mL}^{-1}$ PEAI solution was used. So, this solution is adopted to fabricate all the PSCs hereinafter. Figure 4c provides the statistical PCEs of 20 independent PSCs based on the $\mathrm{CsPbIBr}$ films without and with interfacial voids, which were measured under simulated AM $1.5 \mathrm{G}$ illumination $\left(100 \mathrm{~mW} \mathrm{~cm}^{-2}\right)$ and a scan rate of $10 \mathrm{mV} \mathrm{s}^{-1}$. A black mask containing a circular aperture with specific area of $0.085 \mathrm{~cm}^{2}$ was used to confine the active area of the PSCs. Accordingly, the average PCEs are estimated to be $5.22 \pm 0.54 \%$ and $9.54 \pm 0.59 \%$ for the PSCs fabricated with $\mathrm{CsPbIBr}_{2}$ films without and with interfacial voids, respectively. It is extremely surprised that the $\mathrm{CsPbIBr}_{2}$ films with interfacial voids can enable over $85 \%$ enhancement in average PCE of carbon-based, all-inorganic PSCs. Figure $4 d$ shows the (a)
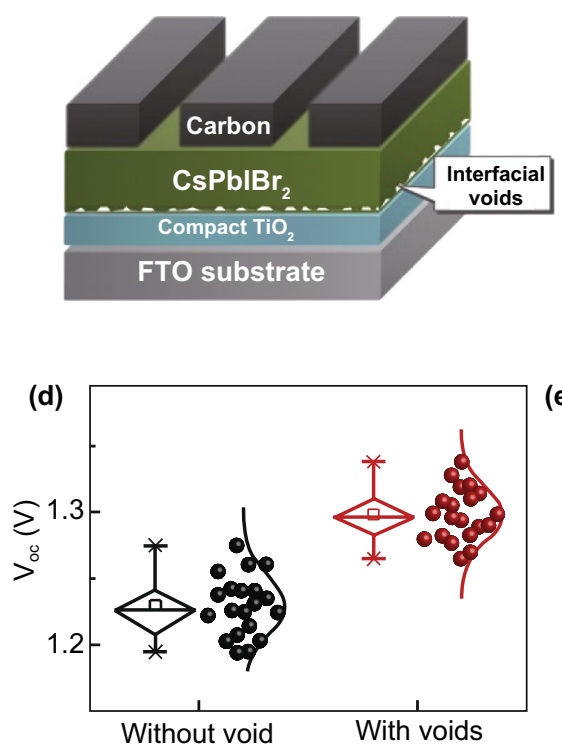

Sample mark

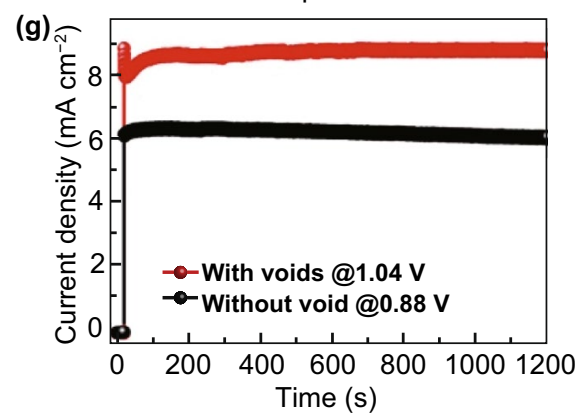

(b)
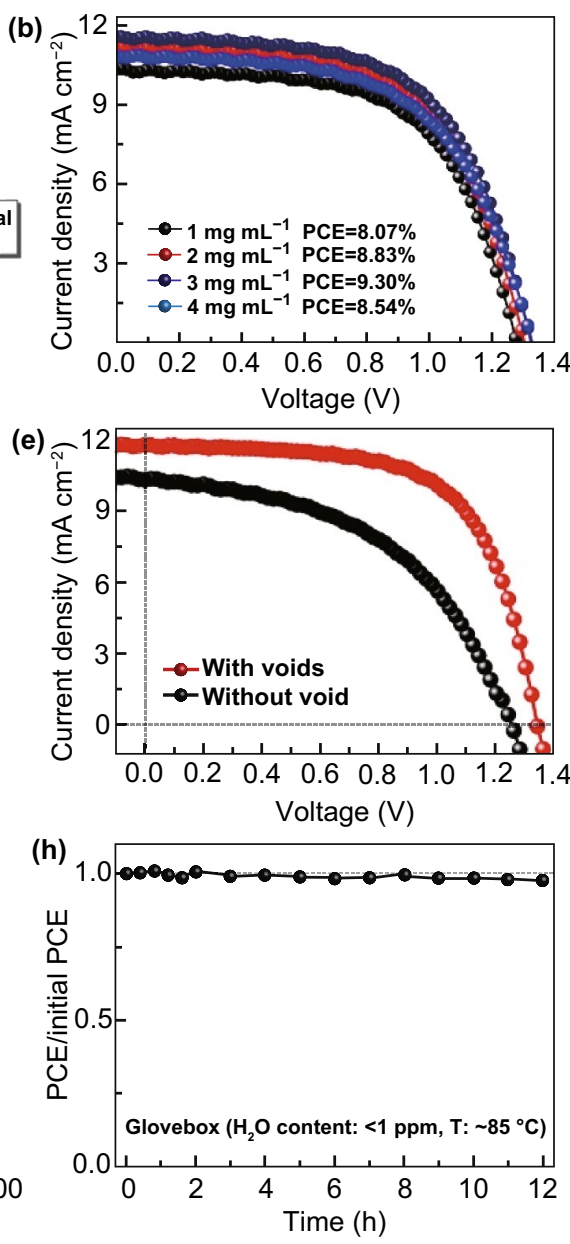
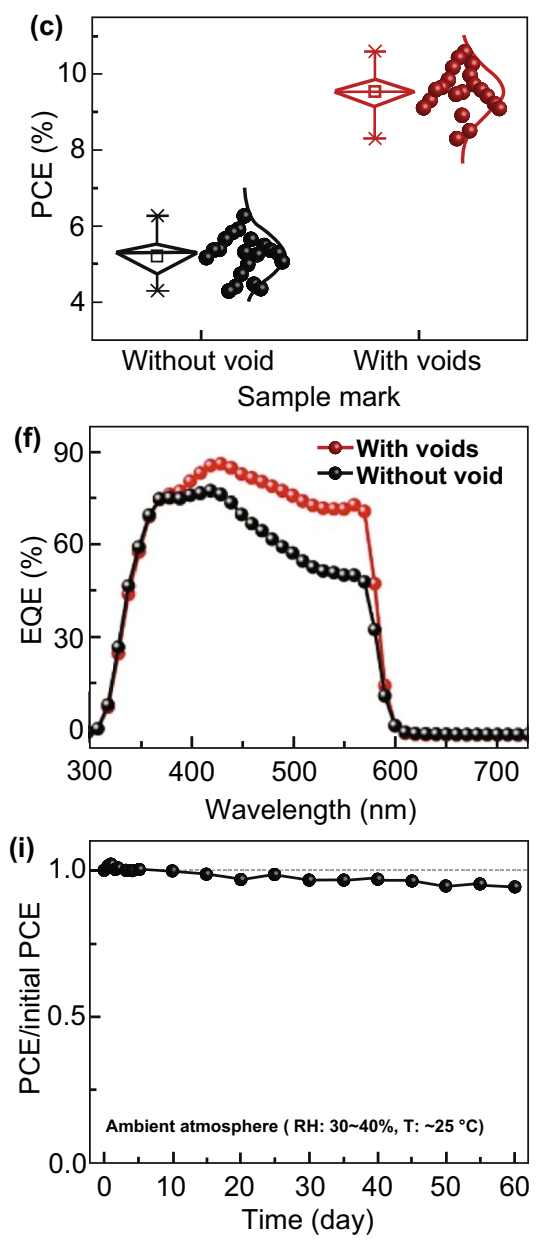

Fig. 4 a Schematic layer stacking of carbon-based, all-inorganic $\mathrm{CsPbIBr}_{2} \mathrm{PSC}$, b typical $J-V$ curves of the PSCs employed CsPbIBr ${ }_{2}$ films prepared with different concentrations of PEAI solutions, c statistic PCEs and $\mathbf{d} V_{\mathrm{oc}}$ distributions of 20 independent $\mathrm{PSCs}$ based on CsPbIBr ${ }_{2}$ films without and with interfacial voids, $\mathbf{e} J-V$ curves, $\mathbf{f}$ EQE spectra, and $\mathbf{g}$ steady-state photocurrent outputs of the champion PSCs based on $\mathrm{CsPbIBr}_{2}$ films without and with interfacial voids. Time-dependent variations of PCEs of the un-encapsulated PSC based on CsPbIBr $\mathrm{Pilm}_{2}$ with interfacial voids in $\mathbf{h}$ glovebox atmosphere and $\mathbf{i}$ ambient condition 
statistical $V_{\text {oc }}$ values of as-fabricated PSCs, from which the average $V_{\mathrm{oc}}$ values are estimated to be $1.230 \pm 0.023$ and $1.297 \pm 0.018 \mathrm{~V}$ for the PSCs based on $\mathrm{CsPbIBr}_{2}$ films without and with interfacial voids, respectively. Thus, we can conclude that the $V_{\text {oc }}$ values of the PSCs based on $\mathrm{CsPbIBr}_{2}$ films with interfacial voids are larger consistently. It is worth noting that the superior $V_{\mathrm{oc}}$ is not only vital to overcome the PCE obstacle facing current $\mathrm{CsPbIBr}_{2}$ PSCs, but also can promote their applications in other energy conversion systems, such as water splitting cells [11, 17, 28].

Figure $4 \mathrm{e}$ displays the current density versus voltages $(J-V)$ curves of the best-performing PSCs employed $\mathrm{CsPbIBr}_{2}$ films without and with interfacial voids, respectively. The typical photovoltaic parameters including $V_{\mathrm{oc}}, \mathrm{FF}, J_{\mathrm{sc}}$, and PCE are provided in Table 1. The

Table 1 Photovoltaic parameters of best-performing PSCs based on $\mathrm{CsPbIBr}_{2}$ films without and with interfacial voids

\begin{tabular}{llllc}
\hline Cells & $V_{\mathrm{oc}}(\mathrm{V})$ & $\mathrm{FF}$ & $J_{\mathrm{sc}}\left(\mathrm{mA} \mathrm{cm}^{-2}\right)$ & PCE $(\%)$ \\
\hline Without void & 1.254 & 0.49 & 10.31 & 6.34 \\
With voids & 1.338 & 0.65 & 11.73 & 10.20 \\
\hline
\end{tabular}

PSC fabricated with $\mathrm{CsPbIBr}_{2}$ film with interfacial voids delivers the $V_{\text {oc }}$ of $1.338 \mathrm{~V}$, FF of 0.65 , and $J_{\text {sc }}$ of $11.73 \mathrm{~mA} \mathrm{~cm}^{-2}$, leading to a much higher PCE of $10.20 \%$. Such PCE is beyond nearly all the $\mathrm{CsPbIBr}_{2}$ PSCs reported previously. More importantly, as shown in Table 2, the $V_{\text {oc }}$ achieved herein stands the highest value among them $[8$, 17-20, 25-27, 30, 31, 35, 47, 48, 51-56].

External quantum efficiency (EQE) spectra of the champion PSCs are given in Fig. 4f. Photocurrent response of each PSC is consistent with the absorption feature of $\mathrm{CsPbIBr}{ }_{2}$ film. By contrast, the PSC based on $\mathrm{CsPbIBr}_{2}$ film with interfacial voids exhibits much higher EQEs in the wavelength regions from 400 to $580 \mathrm{~nm}$, disclosing its better photoelectric conversion capability as a result of higher light absorption and more energetic extraction of charge carriers. Moreover, a remarkable EQE peak of $86 \%$ can be realized in the PSC. In addition, the integrated current densities from the EQE spectra (Fig. S10) are basically consistent with the $J_{\text {sc }}$ provided in Table 1, wherein the discrepancies may be resulted from the absence of light soaking during EQE tests and the spectral mismatch [30, 31, 52].

Table 2 Summary of $V_{\mathrm{oc}}$ values and PCEs for $\mathrm{CsPbIBr}_{2}$ PSCs reported so far

\begin{tabular}{|c|c|c|c|c|}
\hline Cell configuration & $E_{\mathrm{g}}(\mathrm{eV})$ & $V_{\text {oc }}(\mathrm{V})$ & PCE $(\%)$ & Refs. \\
\hline $\mathrm{FTO} / \mathrm{c}-\mathrm{TiO}_{2} / \mathrm{CsPbIBr}_{2} /$ Carbon & 2.07 & 1.338 & 10.20 & This work \\
\hline $\mathrm{FTO} / \mathrm{TiO}_{2} / \mathrm{SmBr}_{3} / \mathrm{Sm}$-doped CsPbIBr$/ 2 /$ spiro-OMeTAD/Au & 2.11 & 1.17 & 10.88 & {$[30]$} \\
\hline $\mathrm{FTO} / \mathrm{c}-\mathrm{TiO}_{2} / \mathrm{CsBr} / \mathrm{CsPbIBr}_{2} /$ Carbon & 2.05 & 1.261 & 10.71 & {$[18]$} \\
\hline $\mathrm{FTO} / \mathrm{TiO}_{2} / \mathrm{CsPb}(\mathrm{Ba}) \mathrm{IBr}_{2} /$ spiro-OMeTAD/Au & $\sim 2.11$ & 1.19 & 10.51 & {$[31]$} \\
\hline $\mathrm{ITO} / \mathrm{SnO}_{2} / \mathrm{S}$-doped $\mathrm{CsPbIBr} / \mathrm{P} 3 \mathrm{HT} / \mathrm{Au}$ & 2.05 & 1.30 & 9.78 & {$[25]$} \\
\hline $\mathrm{FTO} / \mathrm{c}-\mathrm{TiO}_{2} / \mathrm{CsPbIBr}_{2} /$ Carbon & 2.05 & 1.245 & 9.16 & {$[19]$} \\
\hline $\mathrm{FTO} / \mathrm{c}-\mathrm{TiO}_{2} / \mathrm{CsPbIBr}_{2} /$ Carbon & 2.05 & 1.283 & 8.60 & {$[51]$} \\
\hline ITO/SnO $2 / \mathrm{CsPbIBr}_{2} /$ spiro-OMeTAD/Ag & 2.00 & 1.15 & 8.54 & {$[52]$} \\
\hline $\mathrm{FTO} / \mathrm{c}-\mathrm{TiO}_{2} / \mathrm{m}^{-\mathrm{TiO}_{2}} / \mathrm{CsPbIBr}_{2} /$ Carbon & 1.90 & 1.08 & 8.25 & {$[8]$} \\
\hline $\mathrm{FTO} / \mathrm{c}-\mathrm{TiO}_{2} / \mathrm{CsPbIBr}_{2} /$ spiro-OMeTAD $/ \mathrm{Au}$ & 2.05 & 1.227 & 8.02 & {$[47]$} \\
\hline ITO/SnO ${ }_{2} \mathrm{C} 60 / \mathrm{CsPbIr}_{2} /$ spiro-OMeTAD/Au & 2.04 & 1.18 & 7.34 & {$[48]$} \\
\hline $\mathrm{FTO} / \mathrm{TiO}_{2} / \mathrm{CsPbIBr}_{2} /$ spiro-OMeTAD/Ag & 2.07 & 1.28 & 7.31 & {$[53]$} \\
\hline ITO/Passivated $\mathrm{SnO}_{2} / \mathrm{CsPbIr}_{2} /$ Carbon & 2.07 & 1.23 & 7.00 & {$[17]$} \\
\hline $\mathrm{FTO} / \mathrm{c}-\mathrm{TiO}_{2} / \mathrm{CsPbIBr}_{2} /$ Carbon & 2.05 & 1.142 & 6.55 & {$[19]$} \\
\hline $\mathrm{FTO} / \mathrm{c}-\mathrm{TiO}_{2} / \mathrm{m}-\mathrm{TiO}_{2} / \mathrm{CsPbIBr}_{2} /$ spiro-OMeTAD $/ \mathrm{Au}$ & 2.05 & 1.121 & 6.30 & {$[54]$} \\
\hline $\mathrm{FTO} / \mathrm{c}-\mathrm{TiO}_{2} / \mathrm{m}^{-\mathrm{TiO}_{2}} / \mathrm{CsPbIB}_{2} /$ Carbon & 1.89 & 0.96 & 6.14 & {$[20]$} \\
\hline $\mathrm{FTO} / \mathrm{In}_{2} \mathrm{~S}_{3} / \mathrm{CsPbIBr}_{2} / \mathrm{Spiro-OMeTAD} / \mathrm{Ag}$ & 2.08 & 1.09 & 5.59 & {$[27]$} \\
\hline $\mathrm{FTO} / \mathrm{NiO}_{\mathrm{x}} / \mathrm{CsPbIBr}_{2} / \mathrm{ZnO} / \mathrm{Al}$ & 2.10 & 1.01 & 5.57 & {$[26]$} \\
\hline $\mathrm{FTO} / \mathrm{NiO}_{\mathrm{x}} / \mathrm{CsPbIBr}_{2} / \mathrm{MoO}_{\mathrm{x}} / \mathrm{Au}$ & 2.08 & 0.85 & 5.52 & {$[35]$} \\
\hline ITO/ZnO/CsPbIBr 2 /spiro-OMeTAD/Ag & 2.06 & 1.04 & 4.8 & {$[55]$} \\
\hline $\mathrm{FTO} / \mathrm{c}-\mathrm{TiO}_{2} / \mathrm{CsPbIBr}_{2} / \mathrm{Au}$ & 2.05 & 0.959 & 4.70 & {$[56]$} \\
\hline
\end{tabular}


We also tested the steady-state photocurrent outputs of the champion PSCs under maximum power-point conditions (Fig. 4g). They exhibit fast light-response, indicating smooth charge extraction. This desired character is mainly relied to large energy difference of conduction band minimums (CBMs) for $\mathrm{CsPbIBr}_{2}$ absorber and $\mathrm{TiO}_{2}$ ETL [18, 51]. One can see that the PSC based on $\mathrm{CsPbIBr}_{2}$ film without interfacial voids yields the stabilized current density of $\sim 6.18 \mathrm{~mA} \mathrm{~cm}^{-2}$ under a constant bias voltage of $0.880 \mathrm{~V}$, which corresponds to a stabilized PCE of 5.44\%. And, the one without interfacial voids exhibits the stabilized PCE of $8.99 \%$ under $1.040 \mathrm{~V}$, which supports the better performance of the PSC fabricated with $\mathrm{CsPbIBr}_{2}$ film with interfacial voids. However, both steady-state PCEs are smaller than those of extracted from $J-V$ curves, indicative of inevitable anomalous $J-V$ hysteresis. The $J-V$ hysteresis is frequently observed in previous $\mathrm{CsPbIBr}_{2} \mathrm{PSCs}$ and primarily related to light-induced phase segregation in $\mathrm{CsPbIBr}_{2}$ films [8, 46-48, 51, 52, 54, 55]. In addition, one can notice that during the test period the photocurrent outputs of both PSCs are stable in ambient atmosphere, revealing their excellent ability against humidity and light attacking.

Finally, thermal stability and long-term stability of the champion PSC prepared with $\mathrm{CsPbIBr}_{2}$ film with interfacial voids were studied. For thermal stability test, the un-encapsulated PSC was continuously heated at $85{ }^{\circ} \mathrm{C}$ on a hotplate in $\mathrm{N}_{2}$-filled glovebox. And, for long-term stability test the same PSC was stored at room temperature in ambient atmosphere with relative humidity of 30-40\%. As shown in Fig. 4h, the PSC can remain $\sim 97 \%$ of its initial PCE after being tested for $12 \mathrm{~h}$, indicative of its superior thermal stability. We attribute this favored aspect to the excellent resistance of $\mathrm{CsPbIBr}_{2}$ film to high temperature, as it is prepared at a higher annealing temperature of $280{ }^{\circ} \mathrm{C}$. In general, the annealing temperatures for its analogs including $\mathrm{CsPbI}_{3}, \mathrm{CsPbI}_{2} \mathrm{Br}$, and $\mathrm{CsPbBr}_{3}$ are 200,160 , and $250{ }^{\circ} \mathrm{C}$, respectively. Figure $4 \mathrm{i}$ provides the result of long-term stability test. The same PSC can sustain $\sim 94 \%$ of its initial PCE after storing for 60 days, making clear its superior long-term stability against humidity and interface degradation. Overall, one can conclude that the $\mathrm{CsPbIBr}_{2}$ film with interfacial voids can enable the carbon-based, all-inorganic PSC with outstanding PCE and record-high $V_{\text {oc }}$, along with excellent operation stability under light, thermal, or humidity stress.

\subsection{Carrier Dynamics}

To gain insight into the relationship between the carrier dynamics and performance of PSCs prepared with $\mathrm{CsPbIr}_{2}$ films without and with interfacial voids, we explored the transport mechanisms in the fabricated PSCs by means of various characterization techniques, including dark $J-V$, light-intensity-dependent $V_{\text {oc }}$, transient photocurrent (TPC), transient photovoltage (TPV), electrochemical impedance spectroscopy (EIS), and Mott-Schottky (M-S) measurements. Figure 5 a gives the dark $J-V$ curves of investigated PSCs. In general, the dark $J-V$ curve of a solar cell is dominated by the diode law. Based on it, the $J_{0}$ can be estimated from the intercept at zero voltage of the linear regression from semi-logarithmic $J-V$ plot in the region close to the diode turn-on voltage $[19,23,57]$. In general, $J_{0}$ is governed by recombination of charge carriers in the cell, wherein a low $J_{0}$ is always companied by the suppressed recombination. Herein, we can see that the PSC based on $\mathrm{CsPbIr}_{2}$ film with interfacial voids exhibits much smaller $J_{0}$ $\left(1.14 \times 10^{-7} \mathrm{~mA} \mathrm{~cm}^{-2}\right)$ than the one without interfacial voids $\left(1.37 \times 10^{-5} \mathrm{~mA} \mathrm{~cm}^{-2}\right)$, indicating the weaker recombination of charge carriers in it. It should be noted that although the larger grains and higher crystallinity can partly decrease $J_{0}$ of the PSC based on $\mathrm{CsPbIBr}_{2}$ film with interfacial voids, we believe that the interfacial voids may dominantly contribute to its much smaller $J_{0}$. This is because the PSC exhibits the similarly lower dark current under high bias voltages such as $1.5 \mathrm{~V}$.

Figure $5 \mathrm{~b}$ presents the plots of $V_{\mathrm{oc}}$ as a function of incident light intensity for the concerned PSCs. One can see that the $V_{\text {oc }}$ improves with the logarithmic light intensity monotonically, revealing the dominant trap-assisted Shockley-Read-Hall recombination in both PSCs [9, 23, 30, 31]. In addition, the PSC based on $\mathrm{CsPbIBr}_{2}$ film without interfacial void shows a slope of $2.08 k_{\mathrm{B}} T / q$, while the one with voids yields a smaller slope of $1.70 k_{\mathrm{B}} T / q$ that is more close to $1 k_{\mathrm{B}} T / q$, where $q$ is the electric charge, $T$ is temperature, and $k_{\mathrm{B}}$ is the Boltzmann constant. These results further confirm that the recombination of charge carries has been greatly suppressed in the PSC based on $\mathrm{CsPbIr}_{2}$ film with interfacial voids.

Figure $5 \mathrm{c}$ gives the TPC curves of the corresponding PSCs, which can reflect the extraction and transport properties of charge carriers. The photocurrent decay constants are estimated to be 2.64 and $1.83 \mu$ s for the PSCs based on 

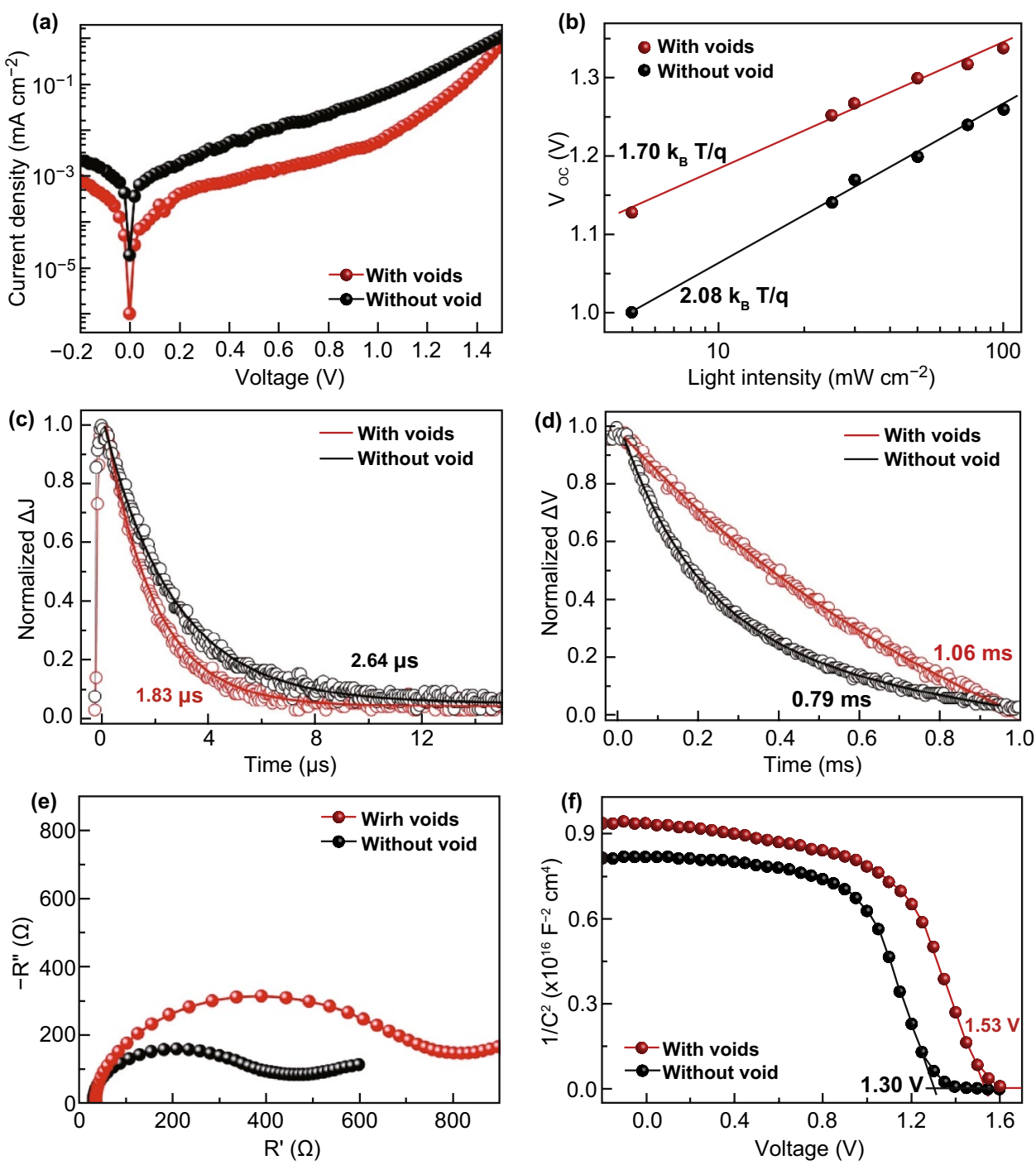

Fig. 5 a Dark $J-V$ curves, b the dependence of $V_{\text {oc }}$ on light intensity, c TPC curves, and $\mathbf{d}$ TPV curves for the PSCs based on CsPbIBr ${ }_{2}$ films without and with interfacial voids, e Nyquist plots and $\mathbf{f} \mathbf{M}-\mathrm{S}$ plots of the same cells

$\mathrm{CsPbIBr}$ film without and with interfacial voids, respectively. These results mean that the interfacial voids do not damage the extraction and transport of charge carriers [18, 19, 51], even though they induce significantly decreased dark current density. Instead, the extraction and transport of charge carriers are improved slightly, which probably benefit from the larger grains and higher crystallinity of $\mathrm{CsPbIBr}_{2}$ film with interfacial voids that endow its better transport ability for photon-generated carriers. At the same time, the recombination of charge carriers in the PSCs is monitored by TPV measurements $[18,19,51]$. The results in Fig. 5d indicate that the PSC based on $\mathrm{CsPbIBr}_{2}$ film with interfacial voids has the slower photovoltage decay $(1.06 \mathrm{~ms})$ than the one without interfacial void $(0.79 \mathrm{~ms})$, which supports the suppressed recombination of charge carriers in the former again.

Furthermore, EIS tests were performed on the fabricated PSCs to estimate recombination resistance $\left(R_{\mathrm{rec}}\right)$ of charge carriers in them $[14,17,25]$. The Nyquist plots that were recorded at a forward bias voltage of $1.0 \mathrm{~V}$ under dark condition are given in Fig. 5e. The clear arc is involved to carrier recombination, reflecting the recombination resistance $R_{\text {rec }}$. The larger $R_{\text {rec }}$ of the PSC based on CsPbIBr ${ }_{2}$ film with interfacial voids is well accordance with the suppressed recombination of charge carriers in it. On the other hand, the $\mathrm{M}-\mathrm{S}$ results in Fig. $5 \mathrm{f}$ indicate that the built-in potential $\left(V_{\mathrm{bi}}\right)$ 
of the PSC based on $\mathrm{CsPbIBr}_{2}$ film with interfacial voids is 1. $56 \mathrm{~V}$, which is much higher than that of the one without interfacial void $\left(V_{\mathrm{bi}}=1.30 \mathrm{~V}\right)$. A larger $V_{\mathrm{bi}}$ not only provide higher driving force to dissociate photo-generated carriers, but also contribute to form a wider depletion region for suppressing recombination of charge carriers in the PSC, as verified by the dark $J-V$, TPV, and EIS results above $[15,18$, $30,31]$. As a whole, the higher $V_{\mathrm{bi}}$ and weaker recombination of charge carriers directly contributes to the record-high $V_{\text {oc }}$ as well as superior FF of the PSC based on $\mathrm{CsPbIBr}_{2}$ film with interfacial voids. And, the higher absorption of $\mathrm{CsPbIBr}_{2}$ film as a result of intense light scattering effect of interfacial voids gives rise to its higher $J_{\mathrm{sc}}$. Therefore, the PCE of the PSC based on $\mathrm{CsPbIBr}_{2}$ film with interfacial voids is improved significantly.

\section{Conclusions}

We demonstrate a new interfacial engineering for carbonbased, inorganic $\mathrm{CsPbIBr}_{2} \mathrm{PSC}_{\text {by manufacturing interfacial }}$ voids between $\mathrm{TiO}_{2}$ ETL and $\mathrm{CsPbIBr}_{2}$ film. The interfacial voids contribute to better absorption, higher $V_{\mathrm{bi}}$, and smaller $J_{0}$ of the PSC, as results of enhanced light scattering in $\mathrm{CsPbIBr}{ }_{2}$ film, boosted crystal quality of $\mathrm{CsPbIBr}_{2}$ grains, and significant suppressed recombination of charge carriers. Consequently, the optimized PSC achieves the PCE of as high as $10.20 \%$ coupled with the $V_{\text {oc }}$ of $1.338 \mathrm{~V}$. Such $V_{\text {oc }}$ represents the best value among $\mathrm{CsPbIBr}_{2} \mathrm{PSCs}$ reported earlier. More promisingly, the non-encapsulated PSC can remain $\sim 97 \%$ and $\sim 94 \%$ of its initial PCE after being heated at $85{ }^{\circ} \mathrm{C}$ for $12 \mathrm{~h}$ or storing in ambient atmosphere with relative humidity of $30-40 \%$ for 60 days, respectively, suggesting its excellent stability against light, thermal, and humidity stresses.

Acknowledgements All the authors gratefully acknowledge the financial support from the National Natural Science Foundation of China (Nos. 61804113, 61874083), Initiative Postdocs Supporting Program (BX20190261), the National Natural Science Foundation of Shaanxi Province (2018ZDCXL-GY-08-02-02 and 2017JM6049), and the Fundamental Research Funds for the Central Universities (JB181107 and JBX171103).

Open Access This article is licensed under a Creative Commons Attribution 4.0 International License, which permits use, sharing, adaptation, distribution and reproduction in any medium or format, as long as you give appropriate credit to the original author(s) and the source, provide a link to the Creative Commons licence, and indicate if changes were made. The images or other third party material in this article are included in the article's Creative Commons licence, unless indicated otherwise in a credit line to the material. If material is not included in the article's Creative Commons licence and your intended use is not permitted by statutory regulation or exceeds the permitted use, you will need to obtain permission directly from the copyright holder. To view a copy of this licence, visit http://creativecommons.org/licenses/by/4.0/.

Electronic supplementary material The online version of this article (https://doi.org/10.1007/s40820-020-00425-1) contains supplementary material, which is available to authorized users.

\section{References}

1. A. Kojima, K. Teshima, Y. Shirai, T. Miyasaka, Organometal halide perovskites as visible-light sensitizers for photovoltaic cells. J. Am. Chem. Soc. 131, 6050-6051 (2009). https ://doi.org/10.1021/ja809598r

2. H.S. Jung, N.G. Park, Perovskite solar cells: from materials to devices. Small 11, 10-25 (2015). https://doi.org/10.1002/ smll.201402767

3. Y. Rong, Y. Hu, A. Mei, H. Tan, M.I. Saidaminov et al., Challenges for commercializing perovskite solar cells. Science 361, eaat8235 (2018). https://doi.org/10.1126/scien ce.aat 8235

4. M. Saliba, J.P. Correa-Baena, M. Grätzel, A. Hagfeldt, A. Abate, Perovskite solar cells: from the atomic level to film quality and device performance. Angew. Chem. Int. Ed. 57, 2554-2569 (2018). https://doi.org/10.1002/anie.201703226

5. Cell efficiency chart. https://www.nrel.gov/pv/cell-efficiency .html. Accessed: Aug 2019

6. C.C. Boyd, R. Cheacharoen, T. Leijtens, M.D. McGehee, Understanding degradation mechanisms and improving stability of perovskite photovoltaics. Chem. Rev. 119, 34183451 (2019). https://doi.org/10.1021/acs.chemrev.8b00336

7. J. Liang, C. Wang, Y. Wang, Z. Xu, Z. Lu et al., All-inorganic perovskite solar cells. J. Am. Chem. Soc. 138, 1582915832 (2016). https://doi.org/10.1021/jacs.6b10227

8. J. Liang, P. Zhao, C. Wang, Y. Wang, Y. Hu, G. Zhu, L. $\mathrm{Ma}$, J. Liu, Z. Jin, $\mathrm{CsPb}_{0.9} \mathrm{Sn}_{0.1} \mathrm{IBr}_{2}$ based all-inorganic perovskite solar cells with exceptional efficiency and stability. J. Am. Chem. Soc. 139, 14009-14012 (2017). https://doi. org/10.1021/jacs.7b07949

9. J. Duan, Y. Zhao, B. He, Q. Tang, High-purity inorganic perovskite films for solar cells with $9.72 \%$ efficiency. Angew. Chem. Int. Ed. 57, 3787-3791 (2018). https://doi. org/10.1002/anie.201800019

10. J. Zhang, G. Hodes, Z. Jin, S. Liu, All-inorganic $\mathrm{CsPbX}_{3}$ perovksite solar cells: progress and prospects. Angew. Chem. Int. Ed. 58, 15596-15618 (2019). https://doi.org/10.1002/ anie. 201901081 
11. A. Ho-Baillie, M. Zhang, C.F.J. Lau, F.-J. Ma, S. Huang, Untapped potentials of inorganic metal halide perovskite solar cells. Joule 3, 938-955 (2019). https://doi. org/10.1016/j.joule.2019.02.002

12. S. Xiang, Z. Fu, W. Li, Y. Wei, J. Liu et al., Highly air-stable carbon-based $\alpha-\mathrm{CsPbI}_{3}$ perovskite solar cells with a broadened optical spectrum. ACS Energy Lett. 3, 1824-1831 (2018). https://doi.org/10.1021/acsenergylett.8b00820

13. S. Xiang, W. Li, Y. Wei, J. Liu, H. Liu, L. Zhu, S. Yang, H. Chen, Natrium doping pushes the efficiency of carbon-based $\mathrm{CsPbI}_{3}$ perovskite solar cells to $10.7 \%$. iScience 15, 156 (2019). https://doi.org/10.1016/j.isci.2019.04.025

14. X. Zhang, Y. Zhou, Y. Li, J. Sun, X. Lu et al., Efficient and carbon-based hole transport layer-free $\mathrm{CsPbI}_{2} \mathrm{Br}$ planar perovskite solar cells using PMMA modification. J. Mater. Chem. C 7, 3852-3861 (2019). https://doi.org/10.1039/ C9TC00374F

15. Y. Guo, F. Zhao, J. Tao, J. Jiang, J. Zhang, J. Yang, Z. Hu, J. Chu, Efficient and hole-transporting-layer-free $\mathrm{CsPbI}_{2} \mathrm{Br}$ planar heterojunction perovskite solar cells through rubidium passivation. ChemSusChem 12, 983-989 (2019). https ://doi.org/10.1002/cssc.201802690

16. X. Meng, Z. Wang, W. Qian, Z. Zhu, T. Zhang et al., Excess cesium iodide induces spinodal decomposition of $\mathrm{CsPbI}_{2} \mathrm{Br}$ perovskite films. J. Phys. Chem. Lett. 10, 194-199 (2019). https://doi.org/10.1021/acs.jpclett.8b03742

17. Z. Guo, S. Teo, Z. Xu, C. Zhang, Y. Kamata, S. Hayase, T. Ma, Achievable high $\mathrm{V}_{\mathrm{oc}}$ of carbon based all-inorganic $\mathrm{CsPbIBr}_{2}$ perovskite solar cells through interface engineering. J. Mater. Chem. A 7, 1227-1232 (2019). https://doi. org/10.1039/C8TA09838G

18. W. Zhu, Z. Zhang, W. Chai, Q. Zhang, D. Chen et al., Band alignment engineering towards $10.71 \%$-efficiency carbonbased, all-inorganic planar $\mathrm{CsPbIBr}_{2}$ perovskite solar cells. ChemSusChem 12, 2318 (2019). https://doi.org/10.1002/ cssc. 201900611

19. W. Zhu, Q. Zhang, C. Zhang, Z. Zhang, D. Chen, Z. Lin, J. Chang, J. Zhang, Y. Hao, Aged precursor solution toward low-temperature fabrication of efficient carbon-based allinorganic planar $\mathrm{CsPbIB}_{2}$ perovskite solar cells. ACS Appl. Energy Mater. 1, 4991-4997 (2018). https://doi.org/10.1021/ acsaem.8b00972

20. J. Liang, Z. Liu, L. Qiu, Z. Hawash, L. Meng et al., Enhancing optical, electronic, crystalline, and morphological properties of cesium lead halide by Mn substitution for highstability all-inorganic perovskite solar cells with carbon electrodes. Adv. Energy Mater. 8, 1800504 (2018). https:// doi.org/10.1002/aenm.201800504

21. X. Liu, X. Tan, Z. Liu, H. Ye, B. Sun, T. Shi, Z. Tang, G. Liao, Boosting the efficiency of carbon-based planar $\mathrm{CsPbr}_{3}$ perovskite solar cells by a modified multistep spin-coating technique and interface engineering. Nano Energy 56, 184-195 (2019). https://doi.org/10.1016/j.nanoe n.2018.11.053

22. J. Liu, L. Zhu, S. Xiang, Y. Wei, M. Xie, H. Liu, W. Li, $\mathrm{H}$. Chen, Growing high-quality $\mathrm{CsPbBr}_{3}$ by using porous
$\mathrm{CsPb}_{2} \mathrm{Br}_{5}$ as an intermediate: a promising light absorber in carbon-based perovskite solar cells. Sustain. Energy Fuels 3, 184-194 (2019). https://doi.org/10.1039/C8SE00442K

23. J. Duan, Y. Zhao, X. Yang, Y. Wang, B. He, Q. Tang, Lanthanide ions doped $\mathrm{CsPbBr}_{3}$ halides for HTM-free $10.14 \%$-efficiency inorganic perovskite solar cell with an ultrahigh open-circuit voltage of 1.594 V. Adv. Energy Mater. 8, 1802346 (2018). https://doi.org/10.1002/aenm.201802346

24. Y. Zhou, Y. Zhao, Chemical stability and instability of inorganic halide perovskites. Energy Environ. Sci. 12, 1495 (2019). https://doi.org/10.1039/C8EE03559H

25. Z. Wang, A.K. Baranwal, M.A. Kamarudin, C.H. Ng, M. Pandey, T. Ma, S. Hayase, Xanthate-induced sulfur doped all-inorganic perovskite with superior phase stability and enhanced performance. Nano Energy 59, 258-267 (2019). https://doi.org/10.1016/j.nanoen.2019.02.049

26. J. Lin, M. Lai, L. Dou, C.S. Kley, H. Chen et al., Thermochromic halide perovskite solar cells. Nat. Mater. 17, 261 (2018). https://doi.org/10.1038/s41563-017-0006-0

27. B. Yang, M. Wang, X. Hu, T. Zhou, Z. Zang, Highly efficient semitransparent $\mathrm{CsPbIBr}_{2}$ perovskite solar cells via lowtemperature processed $\mathrm{In}_{2} \mathrm{~S}_{3}$ as electron-transport-layer. Nano Energy 57, 718-727 (2019). https://doi.org/10.1016/j.nanoe n.2018.12.097

28. M. Moniruddin, B. Ilyassov, X. Zhao, E. Smith, T. Serikov, N. Ibrayev, R. Asmatulu, N. Nuraje, Recent progress on perovskite materials in photovoltaic and water splitting applications. Mater. Today Energy 7, 246-259 (2018). https://doi. org/10.1016/j.mtener.2017.10.005

29. F. Meillaud, A. Shah, C. Droz, E. Vallat-Sauvain, C. Miazza, Efficiency limits for single-junction and tandem solar cells. Sol. Energy Mater. Sol. Cells 90, 2952-2959 (2006). https:// doi.org/10.1016/j.solmat.2006.06.002

30. W.S. Subhani, K. Wang, M. Du, X. Wang, S. Liu, Interfacemodification-induced gradient energy band for highly efficient $\mathrm{CsPbIBr}_{2}$ perovskite solar cells. Adv. Energy Mater. (2019). https://doi.org/10.1002/aenm.201803785

31. W.S. Subhani, K. Wang, M. Du, S.F. Liu, Gold Schmidt-ruledeviated perovskite $\mathrm{CsPbIBr}$ by barium substitution for efficient solar cells. Nano Energy 61, 165-172 (2019). https://doi. org/10.1016/j.nanoen.2019.04.066

32. F. Meng, A. Liu, L. Gao, J. Cao, Y. Yan et al., Current progress in interfacial engineering of carbon-based perovskite solar cells. J. Mater. Chem. A 7, 8690-8699 (2019). https:// doi.org/10.1039/C9TA01364D

33. D.B. Khadka, Y. Shirai, M. Yanagida, K. Miyano, Degradation of encapsulated perovskite solar cells driven by deep trap states and interfacial deterioration. J. Mater. Chem. C 6, 162-170 (2018). https://doi.org/10.1039/C7TC03733C

34. B. Roose, Q. Wang, A. Abate, The role of charge selective contacts in perovskite solar cell stability. Adv. Energy Mater. 9, 1803140 (2019). https://doi.org/10.1002/aenm.201803140

35. C. Liu, W. Li, J. Chen, J. Fan, Y. Mai, R.E. Schropp, Ultrathin $\mathrm{MoO}_{\mathrm{x}}$ as cathode buffer layer for the improvement of allinorganic $\mathrm{CsPbIBr}_{2}$ perovskite solar cells. Nano Energy 41, 75-83 (2017). https://doi.org/10.1016/j.nanoen.2017.08.048 
36. C. Bao, J. Yang, S. Bai, W. Xu, Z. Yan et al., High performance and stable all-inorganic metal halide perovskite-based photodetectors for optical communication applications. Adv. Mater. 30, 1803422 (2018). https://doi.org/10.1002/adma.201803422

37. Q. Jiang, Y. Zhao, X. Zhang, X. Yang, Y. Chen et al., Surface passivation of perovskite film for efficient solar cells. Nat. Photonics 13, 460-466 (2019). https://doi.org/10.1038/s4156 6-019-0398-2

38. Y. Wang, T. Zhang, M. Kan, Y. Zhao, Bifunctional stabilization of all-inorganic $\alpha-\mathrm{CsPbI}_{3}$ perovskite for $17 \%$ efficiency photovoltaics. J. Am. Chem. Soc. 140, 12345-12348 (2018). https://doi.org/10.1021/jacs.8b07927

39. A. Dualeh, P. Gao, S.I. Seok, M.K. Nazeeruddin, M. Grätzel, Thermal behavior of methylammonium lead-trihalide perovskite photovoltaic light harvesters. Chem. Mater. 26, 6160-6164 (2014). https://doi.org/10.1021/cm502468k

40. N.N. Shlenskaya, N.A. Belich, M. Grätzel, E.A. Goodilin, A.B. Tarasov, Light-induced reactivity of gold and hybrid perovskite as a new possible degradation mechanism in perovskite solar cells. J. Mater. Chem. A 6, 1780-1786 (2018). https://doi.org/10.1039/C7TA10217H

41. W. Zhu, C. Bao, B. Lv, F. Li, Y. Yi et al., Dramatically promoted crystallization control of organolead triiodide perovskite film by a homogeneous cap for high efficiency planarheterojunction solar cells. J. Mater. Chem. A 4, 12535-12542 (2016). https://doi.org/10.1039/C6TA04332A

42. G. Gottstein, A. King, L. Shvindlerman, The effect of triplejunction drag on grain growth. Acta Mater. 48, 397-403 (2000). https://doi.org/10.1016/S1359-6454(99)00373-0

43. C. Bi, Q. Wang, Y. Shao, Y. Yuan, Z. Xiao, J. Huang, Nonwetting surface-driven high-aspect-ratio crystalline grain growth for efficient hybrid perovskite solar cells. Nat. Commun. 6, 7747 (2015). https://doi.org/10.1038/ncomms8747

44. F. Chen, Q. Shen, F. Yan, L. Zhang, Pressureless sintering of $\alpha-\mathrm{Si}_{3} \mathrm{~N}_{4}$ porous ceramics using a $\mathrm{H}_{3} \mathrm{PO}_{4}$ pore-forming agent. J. Am. Ceram. Soc. 90, 2379-2383 (2007). https://doi.org/10 $.1111 / \mathrm{j} .1551-2916.2007 .01800 . x$

45. C. Galassi, Processing of porous ceramics: piezoelectric materials. J. Eur. Ceram. Soc. 26, 2951-2958 (2006). https://doi. org/10.1016/j.jeurceramsoc.2006.02.011

46. D.J. Slotcavage, H.I. Karunadasa, M.D. McGehee, Lightinduced phase segregation in halide-perovskite absorbers. ACS Energy Lett. 1, 1199-1205 (2016). https://doi. org/10.1021/acsenergylett.6b00495

47. W. Li, M.U. Rothmann, A. Liu, Z. Wang, Y. Zhang et al., Phase segregation enhanced ion movement in efficient inorganic $\mathrm{CsPbIBr}_{2}$ solar cells. Adv. Energy Mater. 7, 1700946 (2017). https://doi.org/10.1002/aenm.201700946
48. N. Li, Z. Zhu, J. Li, A.K.Y. Jen, L. Wang, Inorganic $\mathrm{CsPb}_{1-\mathrm{x}} \mathrm{Sn}_{\mathrm{x}} \mathrm{IBr}_{2}$ for efficient wide-bandgap perovskite solar cells. Adv. Energy Mater. 8, 1800525 (2018). https://doi. org/10.1002/aenm.201800525

49. I. Gelmetti, N. Montcada, A. Perez-Rodriguez, E. Barrena, C. Ocal et al., Energy alignment and recombination in perovskite solar cells: weighted influence on the open circuit voltage. Energy Environ. Sci. 12, 1309-1316 (2019). https://doi. org/10.1039/C9EE00528E

50. S.M. Kang, S. Jang, J.K. Lee, J. Yoon, D.E. Yoo, J.W. Lee, M. Choi, N.G. Park, Moth-Eye $\mathrm{TiO}_{2}$ layer for improving light harvesting efficiency in perovskite solar cells. Small 12, 24432449 (2016). https://doi.org/10.1002/smll.201600428

51. Q. Zhang, W. Zhu, D. Chen, Z. Zhang, Z. Lin et al., Light processing enables efficient carbon-based, all-inorganic planar $\mathrm{CsPbIBr}_{2}$ solar cells with high photovoltages. ACS Appl. Mater. Interfaces 11, 2997-3005 (2018). https://doi. org/10.1021/acsami.8b17839

52. Y. Jiang, J. Yuan, Y. Ni, J. Yang, Y. Wang, T. Jiu, M. Yuan, J. Chen, Reduced-dimensional $\alpha-\mathrm{CsPbX}_{3}$ perovskites for efficient and stable photovoltaics. Joule 2, 1356-1368 (2018). https://doi.org/10.1016/j.joule.2018.05.004

53. J. Lu, S.-C. Chen, Q. Zheng, Defect passivation of CsPbIBr perovskites for high-performance solar cells with large opencircuit voltage of 1.28 V. ACS Appl. Energy Mater. 1, 58725878 (2018). https://doi.org/10.1021/acsaem.8b01430

54. C.F.J. Lau, X. Deng, Q. Ma, J. Zheng, J.S. Yun, M.A. Green, S. Huang, A.W. Ho-Baillie, $\mathrm{CsPbIBr}_{2}$ perovskite solar cell by spray-assisted deposition. ACS Energy Lett. 1, 573-577 (2016). https://doi.org/10.1021/acsenergylett.6b00341

55. M. Aamir, T. Adhikari, M. Sher, N. Revaprasadu, W. Khalid, J. Akhtar, J.-M. Nunzi, Fabrication of planar heterojunction $\mathrm{CsPbr}_{2} \mathrm{I}$ perovskite solar cells using $\mathrm{ZnO}$ as an electron transport layer and improved solar energy conversion efficiency. New J. Chem. 42, 14104-14110 (2018). https://doi. org/10.1039/C8NJ02238K

56. Q. Ma, S. Huang, X. Wen, M.A. Green, A.W. Ho-Baillie, Hole transport layer free inorganic $\mathrm{CsPbIBr}_{2}$ perovskite solar cell by dual source thermal evaporation. Adv. Energy Mater. 6, 1502202 (2016). https://doi.org/10.1002/aenm.201502202

57. C. Li, Z. Song, D. Zhao, C. Xiao, B. Subedi et al., Reducing saturation-current density to realize high-efficiency lowbandgap mixed tin-lead halide perovskite solar cells. Adv. Energy Mater. 9(3), 1803135 (2019). https://doi.org/10.1002/ aenm.201803135 